\title{
Euthanasia in South Africa: Philosophical and theological considerations
}

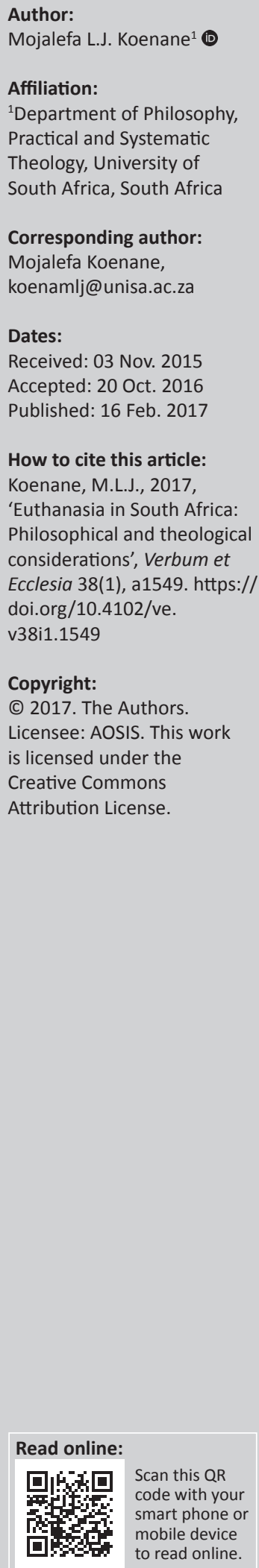

Debates on euthanasia (or 'mercy killing') have been a concern in moral, philosophical, legal, theological, cultural and sociological discourse for centuries. The topic of euthanasia inspires a variety of strong views of which the 'slippery slope' argument is one. The latter warns that the principle(s) underlying any ethical issue (including euthanasia) may be distorted. Scholars' views on euthanasia are influenced mainly by cultural, personal, political and religious convictions. In South Africa, the issue of euthanasia has arisen from time to time, but the question of whether it should be legalised was not seriously considered until it recently attracted attention because of a particular case, that of Cape Town advocate Robin StranshamFord. Although euthanasia is still illegal (this is because the Stransham-Ford ruling is confined to this particular case only), as stated in the ratio decidendi by Judge Hans Fabricius of the High Court in Pretoria, the Court granted leave to appeal its April 2015 judgement regarding euthanasia in the application lodged by Stransham-Ford. In considering the contentious nature of the issue of euthanasia, this article adopts a multidisciplinary approach which includes historical, legal, theological, philosophical, theoretical and analytic frameworks, discussing euthanasia from philosophical and theological perspectives, in particular. We conclude by recommending that the subject of applied ethics, which helps to educate citizens about contemporary moral problems such as euthanasia, be introduced at school level. Exposing young people to the debates around thorny issues such as this would familiarise them with the discourse, encourage them to engage with it and empower them as mature citizens to make informed, reasonable decisions, obviating confusion and conflict which might otherwise arise. The problems surrounding the issue of euthanasia are multidimensional and have the capacity to polarise the nation and destroy families.

Intradisciplinary and/or interdisciplinary implications: The article challenges government tendencies to decide on its own to make policy decisions on which society does not have input; thus against the Batho Pele principle of participation. We suggest that applied ethics be introduced earlier at the school level and be carried onto tertiary education to ensure effective citizen participation.

\section{Introduction}

According to Kuhse (1993:294), the word 'euthanasia' is derived from two Greek words, eu, which means good, and thanatos, the literal meaning of which is death. In its literal sense, then, euthanasia means 'good death'. The idea of a good death may mean different things to different people, but generally speaking, we take it for granted that reasonable persons would agree that a good death means dying painlessly and free of stress. Accordingly, Gonsalves (1985:207) argues that mercy killing is the giving of an easy painless death to one suffering from an incurable or agonizing ailment'. According to Benatar (2011:207), 'for some people, the prospect of continuing in a minimally conscious or unconscious state for the rest of their biological life is a fate worse than death'. Benatar, Benatar and Abratt (1997:2) take this particular point to a much higher level when they argue that terminal illness should be interpreted disjunctively with 'intractable and unbearable illness'. In other words, this argument suggests that in a case where euthanasia is permitted to those whose death is imminent, it would be unjust to deny it to patients suffering chronic conditions without treatment or any possibility of cure. These authors write:

Intractable and unbearable illness [as opposed to 'terminal illness'] means a bodily disorder that (1) cannot be cured or successfully palliated, and (2) that causes such severe suffering that death is preferable to continued life. (Benatar et al. 1997:2)

This argument suggests that there are cases where dying a dignified and painless death is preferred to living a meaningless life without any hope of getting better. In a pragmatic, literal sense, there are important questions that arise: Who does not wish for a good death for himself or 
herself or a close relative? But further, more difficult, questions about euthanasia should be asked. What precisely is 'good death?' 'Good death' for whom? Looked at from a different perspective, the Roman Catholic Church's doctrine on abortion, as articulated in the Declaration on Procured Abortion (in Flannery 1981:No. 1), is pertinent and suggests an answer to the question posed by Michell. According to this document, when accelerating death even in cases where death is foreseen, euthanasia is regarded as murder. The Declaration on Procured Abortion suggests that every effort must still be made to save life. Pain, not a person, must be killed. Insofar as the Declaration on Procured Abortion (Flannery 1981:No. 1) is concerned, the distinction is further made on foreseeing death as a consequence when a doctor administers a strong painkiller, which in the process of fighting pain could also bring about the patient's death, that is, the principle of double effect. By implication, the death of the patient must not be directly intended even if it is foreseen. We argue that Michell's argument is logically flawed, since foreseeing a person's death and suffering does not necessarily translate into sympathetic euthanasia by administering a lethal injection.

The recent South African High Court decision to allow euthanasia has polarised many people regarding their stance on the matter. Euthanasia or mercy killing has been illegal, but recently the Gauteng North High Court (April 2015) held that euthanasia is lawful. The case refers to the request by Stransham-Ford in the Gauteng North High Court (of 29 April 2015) to have medical doctors help him to end his life. The decision of the court does not mean that euthanasia is now legalised in South Africa. The implication is rather that each case has to be taken in context and considered on its own merit. This was a provincial decision and not a parliamentarian decision. The importance of this particular judgement is that it sets a precedent with regard to similar cases in the future. A number of important legal and ethical factors informed Judge Fabricius' decision, of particular interest for the purpose of this article is his statement about euthanasia:

in the absence of legislation, which is the government's prerogative, any other court will scrupulously scrutinize the facts before it, and will determine on a case-by-case basis, whether any safeguards against abuse are sufficient.

This decision was preceded by the recommendation made by the Law Commission in 1999 to legalise passive euthanasia or assisted suicide. No decision was taken on the position on the issue of active euthanasia or assisted suicide, where one actively does something, such as administering a lethal dose of a drug, to hasten death. The decision of the Gauteng North High Court has been challenged among others by the National Minister of Health, Dr Aaron Motsoaledi; the South African Catholic Bishops' Conference; and other religious movements. This ruling was not only challenged by the Department of Health but also by the Department of Justice and Correctional Services through its spokesperson, Mr Michael Masutha, as well as the Health Professions Council of South Africa (Manyathi-Jele 2015).
Essentially, those who challenge this particular court decision do so on the basis that euthanasia is not yet lawful and will remain a moral problem and a misnomer in South Africa until the decision is ratified by the Constitutional Court. Landman as cited by de Lange (2015) hailed the ruling as a 'huge victory' for Stransham-Ford and for Dignity South Africa (i.e. the organisation that advocates for assisted suicide in South Africa). However, Landman further expressed his concern that the Stransham-Ford ruling by Judge Hans Fabricius was specific to, and confined to, this particular case, suggesting that until parliament (the legislature) decides to adopt the draft legislation on euthanasia, other patients who find themselves in a similar situation would have to approach courts individually. However, Landman ${ }^{1}$ (2001:215) argues that euthanasia could be considered on the basis of consistency and fairness in terms of the Constitution. In support of a constitutional justification for the legalisation of euthanasia in South Africa, Landman (2001:215) puts forward the Constitutional Court Case in the Soobramoney case of 1997, in which the applicant demanded the right to be treated, regardless of the hospital's limited resources, to provide for his deteriorating health when he was in desperate need of dialysis. Landman argues that in such a situation, the least the hospital could have done was to have allowed $\mathrm{Mr}$ Soobramoney to die with dignity, since the hospital did not have enough resources to treat everybody. Landman (2001) asserts:

It would be inconsistent, as well as cruel, if the state were also to deny the 'condemned' man's request for physician-assisted suicide or voluntary euthanasia so that he could die sooner and perhaps with less suffering. (p. 215)

This is a compelling argument, particularly when one takes into account the limited health care resources in most government hospitals and when considering the reality that most people in South Africa cannot afford private medical facilities.

The polarisation of thinking about euthanasia is influenced by varying religious, cultural, political, sociological and personal convictions of the general public and of the people seeking assisted suicide. Furthermore, the euthanasia debate raises numerous moral dilemmas. The nature of these dilemmas makes it difficult to establish common ground when making decisions about euthanasia. For some it is about compassion, for others it is assisted suicide, while for yet others it represents murder. Therefore, finding consensus regarding moral issues will always remain a difficult task and must also involve an attempt to understand the real issues surrounding euthanasia, such as respect for autonomy, dying with dignity or being condemned to live an undignified life.

Although opinions on euthanasia differ and there are as many views as there are people, it is argued here that South Africa needs to decide about euthanasia in order for the country to move forward. In this article, we discuss different

1.Prof Willem Landman is an ethicist and was the CEO of the Ethics Institute of South Africa and a champion of Dignity South Africa, a non-profit organisation that advocates for assisted suicide. 
theoretical positions. Furthermore, this simple interpretation of mercy killing suggests that euthanasia could take place as a result of a request by a patient or a relative to a medical practitioner to administer such an intervention. Therefore, in this sense, euthanasia is active and deliberate. Further, we need to bear in mind the distinction between two forms of euthanasia: active and passive. In principle, active euthanasia is a practice in which an intervention or action is taken to end someone's life, whereas passive euthanasia is regarded as allowing death to take place by not administering treatment or intentionally withdrawing medical treatment which could prolong life (this is specifically pertinent to patients without a reasonable hope of recovering). We further argue that euthanasia is not only a philosophical, theological, sociological, psychological, political, economic or legal matter but also a phenomenological issue and as such needs to be discussed in the public domain. At the moment, only rich people can seriously consider euthanasia as an option: the poor cannot consider it. The aim of this article is not to prescribe any specific answer in dealing with the principle of euthanasia, but to make a case for participation and raising the consciousness of South African citizens to engage in debate and take a stance. Ways to stimulate debate could include introducing applied ethics early, even at school level, and sustaining this throughout tertiary education. Knowledge of the issues and public debate will encourage citizens to participate in, engage with and contribute constructively to policy decision-making.

Outside the legal profession and the disciplines of philosophy and theology, not much has been written in South Africa on euthanasia. It is for this reason that this article draws on Western moral philosophical trends in the form of utilitarianism and deontology. Further, the article challenges philosophers to engage in these issues publicly and inform the nation on how to use philosophical theories and thus influence policy. We conclude that the South African government needs to begin dealing openly and seriously with moral issues such as euthanasia, abortion, gay and lesbian rights and other controversial issues in order to avoid political instability and embarrassment by reacting to euthanasia and other moral issues in an uninformed, mechanical way. Employing avoidance strategies will be counterproductive and perpetuate dissent in this country on moral issues.

\section{Understanding euthanasia}

Eschewing the entanglements of the 'slippery slope' arguments, where Nigel Biggar (2004:84), the Christian ethicist, perceives society to be sliding inevitably towards abuse and permissiveness, there are at least three or more moral perspectives through which we can observe human conduct. The 'slippery slope' view of euthanasia or assisted suicide could be defined as an argument which permits euthanasia in a qualified way, such as incurable illness which causes unbearable suffering for a patient without the probability of cure. However, the justification is usually extended to intractable suffering and other chronic illnesses that euthanasia becomes open to. Thus, the 'slippery slope' argument constitutes a warning about the dangers of abuse if euthanasia is allowed in certain cases.

Michell (2002:227) asks a crucially important ethical question: 'Is death by euthanasia foreseen or intended?' In his criticism of the 'slippery slope' argument, Benatar (2011) argues:

Opponents of a legal right to die thus point to the Netherlands, for example, and note how the law permitting euthanasia and doctor-assisted suicide in that country has become steadily more permissive. At first, euthanasia was permitted only for the terminally ill who requested it, but then it was permitted for the chronically ill, for those whose suffering was psychological, and for incompetent patients, including children. (p. 206)

This gives a proper context to Michell's question regarding euthanasia. Michell rightly points out that a decision to live or die will always remain a moral question, especially in cases where death does not occur naturally. Evidently, Benatar (2011:206) rejects as illogical the rhetoric of the 'slippery slope'. The above citation tests the logic of what Benatar identifies as the hidden assumption in the 'slippery slope' argument: 'that the instances of euthanasia that the Netherlands now permits are morally wrong' (Benatar 2011:206). In his model of the responsible life, Biggar (2004:84) insists that human beings are 'equally responsible for all the foreseen effects of the acts that we choose to perform'. Therefore, an important question regarding euthanasia is: What should the moral principles guiding human beings about euthanasia be based on?

Basically, morality is concerned with assessing human behaviour from a point of view based on values. In general, ethicists all agree that we can differentiate between two kinds of human acts: those that are teleologically oriented and those that emphasise a deontological moral aspect. From a philosophical perspective, teleological refers to ethical theories which focus on the end results of human action, whereas the deontological perspectives are duty or obligation oriented. But the question of values is not an easy one to answer since values arise from different perspectives and diverse human backgrounds and experiences. Euthanasia implies causing the death of another person deliberately. Morally, it makes no distinction between cases where an individual is free to act but nevertheless decides against it. When there is an obligation to act in one way or another, not acting still remains a moral decision. In other words, refraining from action is regarded as the result of a choice.

Much as we have outlined one of the approaches to morality to be a normative one, we also believe that ethics is not only normative but also a practical and existential science. As such, ethics must give answers and try to bring about solutions to everyday human problems. Advocates of deliberate or active euthanasia argue that in the case of an ailing person, it is morally permissible to relieve a person from his or her suffering since this person is going to die in any case. Furthermore, advocates of euthanasia differentiate between murder and mercy killing. Put differently, 
proponents of euthanasia argue that not all killing equates to murder. Following the above, we argue that both proponents and opponents of euthanasia should address these moral questions. Until such questions are publicly debated and answered, there will always be difficulties in finding viable solutions to such phenomenological problems.

Voluntary euthanasia occurs when the patient in his or her full senses and with full understanding requests a medical practitioner to end his or her life. This deliberate killing is always for the benefit of the patient and at his or her request. In other cases, it is at the request of family members. It is important to note that even among ancient cultures, euthanasia was practised. The difference in the modern age is that it is more effective, painless and quicker, whereas in ancient times it was brutal ${ }^{2}$ although the intentions were noble. In cases where the patient cannot make a decision, some argue that someone else (a relative) can make a decision for the ailing person. In Singer (1993:294), Kuhse holds the view that such a decision should be for the benefit of the ailing person. Having established euthanasia as a deliberate or voluntary act to assist a patient in achieving death with dignity, it then follows that this act of benevolence should be initiated by the patient, if at all possible. However, Kuhse further articulates that the patient must be a mature, reasonable person who fully understands the moral significance of his or her request. The patient's mental capacity must be intact, and there should be no reasonable hope for recovery within a reasonable period.

Passive euthanasia, or what is generally known as withholding or withdrawing treatment, however, raises another moral problem for those who hold the view that the health profession has a moral obligation to provide necessary treatment (when such treatment is available) to patients in need. Failing to do so is considered as failing in one's moral obligation. Put differently, the medical profession is expected by pro-life advocates to do everything medically and humanly possible to preserve life, in line with the Hippocratic Oath. It is our view that Kuhse (1993) simplifies the Hippocratic Oath by asking these important moral questions about euthanasia:

Does it make a moral difference whether death is actively (or positively) brought about, rather than occurring because lifesustaining treatment is withheld or withdrawn?

Must all available life-sustaining means always be used or are there certain extraordinary or disproportionate means that need not be employed?

Does it make a moral difference whether the patient's death was intended or whether it comes about as a merely foreseen consequence of the agent's action or omission? (p. 296)

However, it is important to note that such a patient must also be in a situation where there is no hope of recovery. In addition, there is involuntary euthanasia, where a patient may not necessarily request the intervention of the doctor to end his or her life, but a decision is made on behalf of the patient without his or her knowledge by a doctor, a friend or any member of the family (this is generally done in secret). Again, this is unethical; a decision to end one's life (mercy killing) is generally supported when the request is made by the patient. This is supported by each person's self-autonomy to decide; further, the very same problem that led to individuals having a final say in the decision to end their lives suggests respect for individual autonomy. To guard the South African Law Commission (Project 86) Discussion Paper 71 on Euthanasia and the Artificial Prevention of Life submitted to the Minister of Health, the following recommendations were taken into consideration by Judge Fabricius in the Stransham-Ford case:

A patient has to be terminally ill and subjected to extreme pain but mentally competent,

A second independent medical practitioner would have to confirm the diagnosis and the findings - these must be recorded in writing,

The request must be based on informed and well-considered decisions and

The request must have been made repeatedly.

Clearly, these factors should be looked at to guard against abuse. The law must also protect the interests of vulnerable patients against abuse by medical practitioners and members of the family. In the next section, we look at normative ethical theories (in philosophy) and assess them in the light of whether they can bring us closer to a viable solution regarding euthanasia or not. These theories are in accordance with the utilitarian and deontological moral approaches. We begin by investigating the early Greek philosophers' positions on euthanasia, specifically Plato and Aristotle.

\section{Philosophical traditions on euthanasia}

Just as on all other issues, philosophers do not see eye to eye insofar as euthanasia is concerned. Some accept it while others reject it. In the next paragraph, therefore, some of the differing positions on the principle in question and its relation to suicide (i.e. self-murder) are presented. Generally, the ancient Greek philosophers attempted to understand everything regarding human experience: some looked at euthanasia from a perspective of suicide which for some was acceptable while for the majority it was taboo. As a result of this majority position, individuals who committed suicide would be given inferior burials outside the city or polis. Positions in matters of ethics were influenced by a number of factors. Given the fact that euthanasia is intentional or a deliberate ending of one's life, it may therefore still be considered as murder.

This must always be understood from the context of a person whose life is no longer meaningful because of illness. In the Republic, Plato (1992) was one of the philosophers who condemned active euthanasia but was sympathetic to passive euthanasia. Passive euthanasia has its own ethical problems, namely 'letting die'. Letting die suggests that there are no 
extraordinary measures that are taken to prolong life. The concept of letting die accommodates withholding treatment of a dying patient. For some people in the health care system, it is the lesser evil than direct euthanasia. Cartwright (1996:354) opines that killing is worse than letting die but also argues that in euthanasia, the significance of the distinction is diminished, but remains important. Cartwright (1996) further elucidates:

[...] one kills someone if one initiates a causal sequence that ends in his [sic] death, whereas one lets him die if one allows an already existing causal sequence to culminate in his death. (p. 354)

However, critics of mercy killing condemn it since they regard it as the duty of the medical professionals (doctors, nurses and health care workers) to do everything in their power to restore life. This is what the Hippocratic Oath is all about. Therefore, some people believe that failing to restore life is also ethically unacceptable. We begin by outlining the utilitarian operating principle, namely maximising happiness for the greatest number.

\section{Utilitarian views on euthanasia}

Utilitarianism is a school of thought in philosophy, the doctrine of which is based on maximising the greatest good for the majority of those affected by a decision or an act (Shaw 2014:46). As such, in their attempt to come to a decision regarding living or dying (consideration of suffering or euthanasia), utilitarianism would ask, in this particular case, what brings about happiness for the greatest number of affected individuals in relation to a patient suffering from incurable illness? Further, utilitarianism is a theory which emphasises the end results in every action. According to Norman (1998:92), utilitarians generally consider euthanasia as producing happiness in a patient who is experiencing agonising pain while death is slowly approaching. Benatar (2011) puts it more bluntly:

To be forced to continue living a life that one deems intolerable when there are doctors who are willing either to end one's life or to assist one in ending one's own life, is an unspeakable violation of an individual's freedom to live and to die as he or she sees fit. (p. 206)

Looked at from this point of view, the consequence of mercy killing is to stop the agony of pain and suffering and bring about painless death, which for utilitarianism is a morally better option than standing by and watching someone die a slow and agonising death. Although euthanasia is deliberate, the intended result is to bring about happiness in comparison with the undignified and agonising pain of a suffering patient. Therefore, for utilitarianism, euthanasia is a moral intervention to minimise pain and maximise happiness in patients for whom there is no hope of recovery. Again, the main argument is that death is unavoidable, but it may be accelerated by means of euthanasia.

For utilitarians, the means through which pain is minimised is of no significance; achieving the intended result is what matters. Therefore, for these theorists, the end justifies the means. There will always be diverse views on moral matters, in particular. But then, what does this have to do with the principle under discussion (i.e. euthanasia)? The basic idea is achieving a balance. That which produces the best results for the greatest number of those involved is the only right course of action for the utilitarian. In this case, we also need to ask this important question: the best results or consequences for whom?

The morality of participation is that the patient's freedom should not be attained if it interferes with the freedom of others, which introduces another moral dilemma, namely the people involved in the patient's decision to die. It implicates a number of people such as the patient (moral agent) who voluntarily requests the termination of his or her life; medical and health care professionals who are also moral agents, both in their personal and their professional calling; members of the family (who may well take different viewpoints on the matter); and finally those involved in the laws of the country. The problem with utilitarianism is that it is difficult to ascertain who ultimately benefits from the death of another, given that there may be selfish reasons behind advocating for euthanasia.

The question of benefit is an important matter for which utilitarian proponents of euthanasia would argue, since it emphasises the maximising of pleasure and the minimising of pain. We argue that pleasure in the utilitarian sense could also include dying with dignity. Undoubtedly, dying a painless and dignified death is correctly viewed as bringing about happiness for the patient and those affected by a long incurable illness of a loved one. Having elucidated this idea of the majority's benefit or happiness as a result of an action, this raises two major problems. Firstly, if the death of a patient suffering from an incurable illness will benefit the greatest number of those affected, this may mean that individual autonomy is irrelevant. It also implies that, from a utilitarian perspective, the decision to end someone's life may well be taken by others and not necessarily by the person in question (the patient). Put differently, individual autonomy is not taken into account. Secondly, when it comes to policy, this may well mean that if the majority in society are against euthanasia, then policy makers will have a problem because individual rights would be completely undermined. If the basic operational principle in utilitarianism is maximising happiness and lessening of pain, it is therefore safe to suggest that euthanasia would be considered a viable option depending on the number of people who may benefit from it. Utilitarianism focuses on the end results for the greatest number and also for the individual. Norman (1998:92) elucidates: 'In practice each person's pursuit of his or her pleasure will be modified to take account of the pleasures and pains of others'. From a philosophical perspective, it is clear that there is a variety of approaches to the ethics of euthanasia. In the next section, we look at euthanasia in terms of deontological ethical theories.

\section{Deontology and euthanasia}

The term 'deontology' is derived from the Greek word deon, meaning duty. In its approach to ethical matters, deontology 
takes a different approach to that of utilitarianism. While utilitarianism measures the rightness and wrongness of an action based on the number of those who benefit from its consequences, for deontology, results are irrelevant. According to Kant from whom deontology originated, human actions are either inherently right or wrong in themselves. Therefore, the consequences or end results are inconsequential. Further, with regard to deontology, Kant (1986:57) holds that what matters to render an action right is good will and good intention. Deontology's further emphasis is on self-legislating will, as noted by Fernandes (2008:16). The self-legislating will is understood as the core of morality in Kant's ethics. In other words, human actions must flow from universal reason, since for him nothing is good except free will. Since the human will (volition) plays an important role in Kantianism, it is possible to bring two of his favourite words together and refer to the 'intentional-will'.

Therefore, for Kant, the end does not justify the means. Insofar as deontology theory is correctly interpreted, euthanasia is a means to an end and, as such, cannot be justified. The principle in Kant's deontology is further disproved by how he formulates one of his classical definitions of the categorical imperative which articulates the maxim that one must act in such a way that one's actions do not treat other persons as means to an end but as ends in themselves. Taking the above as our point of departure, and understanding euthanasia in its full sense that is the intention and will to assist an incurable ailing person to die; such an act is based on a disapproved principle. This is because for Kant the form of the act is of essential concern (Fernandes 2008:16). Further, Loretta Kopelman (2001:87) points out that some major figures in philosophy and theology advocating against euthanasia argue that it (euthanasia) cannot be justified since it intends to destroy God's creation.

In the next section, we focus on the principle of autonomy as offered by supporters of euthanasia as justification for the principle.

\section{Autonomy and euthanasia}

In essence, active euthanasia is a type of mercy killing, which is extremely controversial. However, we have seen that in the Catholic and other religious traditions, all forms of euthanasia are condemned. But there are those who believe that the only authority who can make a moral decision to endure suffering or end it is the suffering person. Individual autonomy concerns itself with individual freedom, especially the freedom of competent patients living an unbearable, restricted life because they are suffering from an incurable illness. We ask these important questions: How free are mature, competent individual(s) to decide their own fate, especially in making a choice between living and dying? Does autonomy mean that a person is free to dispose of his or her life as he or she pleases? Is there a choice between living with a good quality of life and dying with 'dignity' or continuing to live with a poor quality of life and then dying a sad and slow death?
In practice, insofar as opinions about freedom and freedom of choice are concerned, in particular with regard to certain human actions, existentialism may perhaps be a more appropriate theory to adopt. Existentialists are known for their emphasis on freedom of choice to the extent that, for Sartre, human kind is condemned to freedom. So for existentialists, the fundamental principle of human existence is their freedom to choose (Morton 1999:117). Individuals must choose how they want to live their lives. Although freedom is the basis of existentialists' argument, they emphasise that one should then take full responsibility for one's choices. However, the problem where euthanasia is concerned is that there is no way in which the person who requested it can account for or take full responsibility for such action, for obvious reasons.

Autonomy and respect for autonomy are some of the main ideas in Kant's philosophy. In health centres, autonomy means that health care and medicine have moved away from a paternalistic approach to allowing patients to participate fully in their treatment or care. We begin by analysing what Kant (1986:148) understood by autonomy and respect for autonomy. Interestingly, although Kant was one of the advocates of autonomy, he argued against the right of an individual to dispose of his or her own life. Underlying the notion of autonomy is the idea regarding the individual's self-determination. Again we ask: How free is an individual to take his or her own life or even request assistance in doing so? Evidently, attempts to answer these questions are influenced by a number of factors ranging from common sense to more complex and deeply religious ones. For those who argue in support of autonomy and respect for autonomy, euthanasia is more than a demand for the legalisation thereof. They maintain that self-determination promotes freedom to choose to live or die. Generally, those who argue against euthanasia in all its forms base their religious argument on the theory of the sanctity of human life.

In South Africa, patients have a right to refuse medical treatment. This appears to us to support the principle of autonomy or self-determination, but it is still illegal for the doctor or medical professionals to actively assist a patient to die. Demonstrating the complexity of euthanasia, all the following parties need to be taken into account when considering taking so final a step. The issue remains one that divides the public into those who are in support of euthanasia and those who are opposed to it, as well as those who find themselves in between or are undecided. According to Fernandes (2008:5), the principle of euthanasia widely dominates debates in philosophy, politics, religion and theology as well as the legal field. In essence, autonomy is a principle that assumes that moral agents have the competence to make reasonable decisions. Accordingly, respect for autonomy refers to respecting the choices autonomous individuals make irrespective of whether one agrees with such decisions or not. According to Morton (1999:117), existentialism is notably a philosophical theory which asserts the absolute autonomy of moral agents. Ashley and O' Rourke (1982:156-157) take it further, echoing Sartre's view that for the existentialist, a human being is 
condemned to freedom, and as such it is the individual's obligation to decide the course of his or her life. However, in the case of euthanasia, the autonomy of the individual patient is not the only concern. We consider the role of medical professionals who are directly or indirectly involved in the autonomous decision. We focus on the role of individual conscience and the right of a patient to die.

Ronald Dworkin (cited in Fernandes 2008) advances the argument for euthanasia as follows:

\begin{abstract}
It is, however, plausible, and to many people quite compelling, that total dependence is in itself a very bad thing, quite apart from the pain or discomfort it often, but not invariably entails. Total or near dependence with nothing positive to redeem it may seem not only to add nothing to the overall quality of life, but to take something important from it [...] Sunny von Bulow still lies wholly unconscious in a hospital bed in Manhattan; every day she is turned and groomed by people willing and paid to do it [...]. It would have been odd for her not to think, before she fell into her coma, that this kind of pointless solicitude was insulting, itself an affront to her dignity. (p. 165)
\end{abstract}

This further problematises the concept of quality of life or dignity. Human dignity means different things to different people. Advocates against euthanasia in all its forms, which include discontinuing all interventions (palliative care) that could prolong life through other means, are clearly opposed to this method of ending a patient's life.

\section{The Roman Catholic Church's doctrine on euthanasia}

Kuhse (1993:294) points out that in the early Greek and Roman traditions, euthanasia was an accepted practice. Kuhse further asserts that the change in the acceptance of euthanasia came about through religion, more specifically Judaism and Christianity. For both Judaism and Christianity, human life is regarded as sanctified, and as such, life should not be destroyed or taken deliberately. For these and other religious traditions, only God has the right to end life. This is the argument advanced by most religious persons following God's command as prescribed in the Ten Commandments, namely: 'Thou shall not kill'. While most religious people depend on the Divine Command for answers regarding life, philosophers would depend on human reason for the same answers.

The view upheld by Pope John Paul II in his encyclical (John Paul II 1995) is against discontinuation of any intervention that could prolong life. He argues that discontinuing interventions such as these stands in opposition to the Christian understanding of care; thus, it readily translates to refusing to assist a person to live (although suffering) in dignity. In other words, for the Church, suffering from an incurable illness does not necessarily compromise a patient's human dignity: dignity can and should be enhanced by all means necessary. Euthanasia, according to the teaching of the Church, is a violation of the Divine law and an offence against human 'dignity' which proponents of the principle claim to defend.
From a Christian perspective, we have drawn on some of the proclamations of the Catholic Church on euthanasia, such as the Vatican Council II document Pastoral Constitution on the Church in the Modern World (Gaudium et Spes), in Flannery (1981:No. 26) and Pope John Paul's declaration in the Evangelium Vitae of 1995. The opening chapter (Chapter One) of Gaudium et Spes deals with the subtitle 'the dignity of the human person', which emphasises that 'man (sic) was created in the image of God'. But the document does not stop there. It continues to proclaim as infamies all those actions that violate human dignity in any way. Gaudium et Spes No. 26 states the following:

The social order and its development must invariably work to the benefit of human persons if the disposition of affairs is to be subordinate to the personal realm and not counter wise [...]. This social order requires constant improvement. (Gaudium et Spes, in Flannery 1981:No. 26)

The above statement is later on supported in the same document where it proclaims:

Furthermore, whatever is opposed to life itself, such as any type of murder, genocide, abortion, euthanasia or willful selfdestruction, whatever violates the integrity of the human person, [...] are infamies [...]. (Flannery 1981:No. 27)

The cited parts of Gaudium et Spes (No. 26 \& 27) are clear on the Church's teaching on euthanasia and other moral issues. In simple terms, euthanasia is condemned and thus regarded as one of the acts which violate the dignity of a human being, and consequently the Church advocates against mercy killing. In this document (Gaudium et Spes), euthanasia is listed among other kinds of murder. Taking the Catholic Church's doctrine in both the cited texts, it promotes the principle of caring for people in need of such caring and exhorts individuals to promote personal health.

Pope John Paul II's encyclical Evangelium Vitae takes the matter further and is more direct. The encyclical letter was addressed to bishops, priests, deacons, religious men and religious women, as well as the laity. In other words, it was binding to all Catholics. In this encyclical, Pope John Paul II defines euthanasia as follows: 'Euthanasia is an act or omission which of itself or by intention causes death, with the purpose of eliminating suffering' (John Paul II 1995:No. 65). This position raises moral dilemmas for Catholics including patients afflicted with pain and suffering from an incurable illness, patients whose death is imminent, family members who consider euthanasia (active or passive) as an option as well as health workers and medical professionals who are experts in inducing painless death. The Pope's declaration prohibits both active and passive euthanasia. Consequently, an action can be either a completed action which is also referred to as an act of commission or an incomplete act of omission. An act can also refer to what one, through moral obligation, ought to do but intentionally fails to do. In this case (John Paul II 1995), the prohibition of the principle effectively cancels the autonomy of the patient to request euthanasia, contradicting Plato's position. These contradictory positions do not make the situation any easier for Catholic health care workers as well as for 
medical professionals, particularly if they are employed by the State, which has legalised euthanasia. In this encyclical, Pope John Paul II clearly indicates that euthanasia is regarded as interfering with God's plan in the suffering person; further suffering is regarded as part of Christian life in this world. One can strictly interpret the Pope's encyclical as seeing euthanasia as unchristian and as an easy way out of understanding suffering in its rightful context in the life of a committed Christian. The medical argument that medicine nowadays is so advanced that no one has to suffer excruciating pain nullifies the argument that death is the only means of ending pain. Often the argument put forward by proponents of the legalisation of euthanasia is supported by the condition of a patient who is suffering extreme pain.

It is fundamentally important to note that the right to die of a patient who requests euthanasia is equally important as the rights of the medical practitioner who administers it and the nurses who assist in the procedure. My concern is with health care workers who are employed by a government which permits euthanasia in government health centres. The question is: How free are health care workers to refuse to participate in administering mercy killing? In South Africa, the government, through the Ministry of Health, has argued for palliative care (Medical Brief 2015) ${ }^{3}$; (i.e. quality care for the dying and sick persons in order for them to die a dignified death), which renders the euthanasia argument null and void.

This is not an easy question, so we cannot expect an easy answer. Presumably, in a hospital which provides certain services the government has legalised, it is the right of the patient to receive those services without hindrance. We also need to consider the situation of a conscientious objector, whose religion or conscience may not allow him or her to participate in euthanasia but will refer the patient to another doctor. Another question is: What does 'participation' entail? The concept of participation cannot be understood loosely. For example, it could either be direct or indirect. It is direct when the medical practitioner participates willingly in administering painless death to the patient, but it is indirect in the case of a conscientious objector who refers the patient to someone else to perform the service. Undoubtedly, the only logical expectation of a religious person's participation would be to make a serious effort in changing the conscientious objector's mind and convincing him or her otherwise on the matter of euthanasia. The Church would expect its members who are medical practitioners to do everything possible to preserve life rather than end it, even if it means failing to alleviate pain. Therefore, depending on one's understanding of 'participation', one cannot completely abstain from either direct or indirect participation. Although the focus may be on those who participate directly and administer euthanasia, the indirect participator is equally accountable - at least insofar as Pope John Paul II's encyclical of 1995 directs.

3.This was the response by the National Minister of Health in response to the court ruling in favour of assisted suicide by Judge Hans Fabricius in the Robin StranshamFord case.

\section{Conclusion}

Euthanasia is viewed differently by different people, and this issue has polarised citizens. There are as many different points of departure as there are opinions on the matter: for some people, it is about autonomy or about sympathy, while others see it as murder. What is clear is that proponents of all sides argue convincingly in support of their respective positions. It is for this reason we support the position that each case should be considered on its own merit. In other words, the 'one-size-fits-all' policy would not work as a basis on which all cases of euthanasia should be accounted for. We have argued that it is difficult to legislate for euthanasia in South Africa for the simple reason that euthanasia is considered by many as an anomaly. However, Landman's opinion that euthanasia could be considered on the basis of consistency, fairness and in terms of the Constitution offers a viable course of action.

This article brings to light the complexity of the principle of euthanasia. One of these principles is participation by others and the implications for such participation. Our aim was neither to endorse nor to repudiate any position for or against euthanasia, nor was the aim to prescribe what individuals ought to do regarding it, but to show how difficult it is to take a stance if individuals are not educated to make decisions on moral matters. We have argued strongly that the debates around euthanasia and other ethical issues should take place regularly. In some cases, an individual's request for his or her life to be ended could be rational and carried out in a moral way, so it could be regarded as a moral act. Avoidance of debating and dealing with such ethically demanding issues can only breed confusion, intolerance and anger. Given the sensitivity of euthanasia, people must be informed in order to make educated moral decisions about their lives. The debates around euthanasia and other moral matters demonstrate that philosophy and theology are disciplines that take controversial issues in everyday life seriously, and encourage open discussion of ethical issues, thereby contributing to informed policy decisions.

The Stransham-Ford case is valuable in the sense that it has allowed for euthanasia to be robustly and openly debated in legal, political, religious, cultural and sociological fora. Judge Fabricius' judgement in the same case suggests that individual instances of euthanasia should be decided on a case-by-case basis: in this way, there would be no one-size-fits-all policy on such a matter. We argue that the value of moral decisions is viewed on the basis of how well they serve persons in their unique situations. The ability of humankind to make rational decisions on complex, sensitive issues is largely dependent on the existence of a culture of debate in which different points of view are put forward and considered. Such a culture would enable citizens to develop and defend their opinions, based on whatever value system they choose to adopt. The sooner moral issues and applied ethics are introduced into the South African education system and continued throughout higher education, the better prepared citizens will be to participate in policy-making decisions in this country. 


\section{Acknowledgements}

I would like to convey my greatest gratitude to Prof Mogobe Ramose for pointing me towards the argument of 'slippery slope' and advising me to make a mention of the Netherlands, as it epitomises the new dispensation and has taken the lead in terms of legalising euthanasia. I am also indebted to Prof Kgomotso Masemola for his professional editing of this manuscript as well as his scholarliness in academic matters.

\section{Competing interests}

The author declares that he has no financial or personal relationships that may have inappropriately influenced him in writing this article.

\section{References}

Ashley, B.M. \& O' Rourke, K.D., 1982, Health care ethics: A theological analysis, The Catholic Health Association, St. Louis, MO.

Benatar, D., 2011, 'A legal right to die: Responding to slippery slope and abuse arguments', Current Oncology 18(5), 206-207. https://doi.org/10.3747/co. v18i5.923

Benatar, D., Benatar, S.R. \& Abratt, R., 1997, Comments on the draft bill on end-of-life decisions, Department of Medicine, University of Cape Town Press, Cape Town.

Biggar, N., 2004, Aiming to kill: The ethics of euthanasia and suicide, Darton Longman and Todd, London.

Cartwright, W., 1996, 'Killing and letting die: A defensible distinction', British Medical Bulletin 52(2), 354-361. https://doi.org/10.1093/oxfordjournals.bmb.a011550

De Lange, I. 2015, 'Euthanasia ruling "huge victory" for dignity SA', The Citizen, 1 May 2015, p. 3.
Epictetus, 1st and 2nd Century. The discoveries as reported by Arrian. The manual and the fragments, Heinemann, London.

Erdemir, A.D., 2001, 'A short history of Euthanasia law and their place in Turkish Law', Eubios Journal of Asian and International Bioethics 11, 47-49.

Fernandes, A.E., 2008, 'Euthanasia, assisted suicide, and the philosophical anthropology of Karol Wojtyla', Unpublished dissertation submitted for Doctoral Degree in Philosophy, Georgetown University, Washington, DC.

Flannery, A. (ed.), 1981, Vatican Council II the Conciliar and Post-Conciliar Documents: Gaudium et Spes, Costello Publishing Co, New York.

Gonsalves, M.A., 1985, Fagothey's right and reason: Ethics in theory and practice, Times Mirror Mosby College Publishing, St. Louis, MO.

John Paul II., 1995, Evangelium vitae: Papal encyclicals, Vatican City Press, Rome.

Kant, I., 1986, Duties towards the body in regard to life, lectures on ethics, transl. L. Infield, Harper \& Row, New York.

Kopelman, L.M., 2001, 'Does physician-assisted suicide promote liberty and compassion?', in L. Kopelman \& K.A. De Ville (eds.), Physician assisted suicide, pp. 87-102, Kluver Academic Publishers, Dordrecht, The Netherlands.

Kuhse, H., 1993, 'Euthanasia', in P. Singer (ed.), A companion to ethics, pp. 294-302, Blackwell Publishers, Oxford.

Landman, W.A., 2001, 'A proposal for legalizing assisted suicide and euthanasia in South Africa', in L. Kopelman \& K.A. De Ville (eds.), Physician assisted suicide, pp. 203-225, Kluver Academic Publishers, Dordrecht, The Netherlands.

Manyathi-Jele, N., 2015, 'Judge's ruling in assisted suicide case divides South Africa', De Rebus (553), 4-7.

Medical Brief: Africa's Medical Media Digest, 2015, 'The right to die judgement under siege', 05 May 2015.

Michell, L., 2002, 'Euthanasia and/or the end of medical care', Religion and Theology: A Journal of Contemporary Religious Discourse 9(3), 225-245. https://doi. org/10.1163/157430102X00124

Morton, A., 1999, Philosophy in practice: An introduction to the main questions, Blackwell Publishers, Malden, MA.

Norman, R., 1998, The moral philosophers: An introduction to ethics, Oxford University Press, Oxford.

Plato, 1992, Republic 1. The Greeks, Od. Hatzopoudos (ed.), Kaktos Publishers, Athens.

Shaw, W., 2014, Business ethics: International edition, 8th edn., Cengage Learning, Wadsworth, $\mathrm{OH}$. 